\title{
Study on the System of Smart Education in Universities
}

\author{
Zhifeng $\mathrm{Hu}$ \\ Wuhan Business University, Wuhan, Hubei, 430056 \\ hzf@wbu.edu.cn
}

\begin{abstract}
Keywords: Informatization. Smart Education. Big Data. Cloud platform.
Abstract. The organic integration of educational communication, teaching and scientific research, learning activities, educational administration and campus infrastructure can be achieved through the smart education system to support the university construction, including holographic network environment, cloud computing data center, big data analysis application system and multi-dimensional Internet of Things perception system, so as to enable the modern information and communication technology to provide more intelligent, efficient and accurate services for teaching, scientific research, management and life.
\end{abstract}

\section{Introduction}

As the advanced form of modern education information, smart education system can be able to achieve the organic integration of educational communication, teaching and scientific research, learning activities, educational administration and campus infrastructure through the support of cloud computing, big data, Internet of Things and mobile Internet to construct the holographic network environment, cloud computing data center, big data analysis application system and multi-dimensional Internet of Things perception system, so as to enable the modern information and communication technology to provide more intelligent, efficient and accurate services for teaching, scientific research, management and life. In addition, the realization of university construction, reform and development supported by smart education system promotes the deep integration of information technology and the education teaching, realizing the overall enhancement of the education level[1].

\section{Basic Requirements of Smart Education.}

Basic network coverage. A multi-standard, high-speed, fully covered and highly usable basic network is required to realize the interworking between campus wired network buildings, among which, some network is gigabytes to the desktop and wireless network covers the whole school. Moreover, the connected devices, including videoconferencing system, e-card system, campus security and access control (wired and wireless) system, have been employed and involved into the entire network architecture of the whole school [2].

Cloud platform interworking. The data center and computing mode of traditional colleges and universities do not apply the unified management and maintenance, nor is it conducive to information security, easy to result in idle and waste of resources. Therefore, a set of logical integration, physical centralized cloud computing and storage platform should be established to construct the smart campus, which can integrate the resources of business department organically, and cooperate with the cloud management system to distribute and apply the resources to ensure the maximum utilization of resources. In addition, cloud platform can provide a variety of teaching applications with the holographic network environment[3].

Application system integration. As the window and embodiment of the smart education system, the application system of smart education covers the whole process of teaching, scientific research, study and life. In the application environment of colleges and universities, there are not only the demands of faculties and departments, but also the needs of centralized and unified interaction. Therefore, a distributed interactive application system is necessary to establish based on cloud 
computing technology to ensure that teachers, students and managers can achieve the all-around, real-time, and accurate office, teaching, learning and decision-making. In addition, the information system construction requires to integrate data into the smart education application system with the big data technology.

Teaching resources sharing.Besides the coverage of traditional specialty and curriculum, the construction of teaching resources system should emphasize on the accumulation, integration and sharing of teaching resources. Therefore, the sharing, exchange and accumulation of characteristic teaching resources should be taken into account based on the constructing standard smart education teaching resource base, so as to involve the results and experiences from teaching and research of characteristic specialty into teaching resource base, to further enhance the characteristics specialty and the training ability of applied technical talents[4].

\section{Contents of the Smart Education System.}

Campus network. Wired campus network, covers the flat wired campus network and wired network connection system with buildings. Wireless campus network, refers to the whole school covered wireless campus network for campus construction. Integrated pipe network system, unified centralized management platform, achieves the 4A authentication intelligent operation and maintenance management[5].

Infrastructure. Central computer room, plan the campus construction data center computer room, disaster data center computer room, network monitoring computer room and information center office, etc., for the whole school network management. Operation cluster, a cluster computing system built on campus server, carries the core operation requirements. Storage cluster, cluster storage system built based on disk array and storage server on campus, carries the core storage requirements.

Cloud platform.Virtualization platform: establish a virtualization platform to virtualized integrate by the unified technical standards for operations and storage resources.Cloud management platform: the cloud resource management platform is built to manage the virtualized network, operation and storage resources in a unified way, and realize resource allocation according to demand and flexible scheduling.Desktop cloud platform: the desktop cloud platform is built to push the virtualized computing and storage resources to meet the needs of teaching and office applications.Application cloud platform: the application cloud platform is built to push the application of virtualized network, computing and storage resources to meet the requirements of lightweight applications.Cloud security system: the information security system oriented to cloud architecture is built to guarantee information security through infrastructure, information platform and cloud architecture.

Big data platform. Smart education management platform: it is to construct the unified data sharing interaction center and campus information system standard to realize the unified information portal, unified identity authentication and unified single sign-on.Campus big data platform: it is to provide data support services for top level application system based on the data integration, storage, mining and analysis of big data technology.

Application system set. Campus unified management platform, based on the campus network, the integrated management platform integrates all the information resources of teaching, scientific research, management and service with advanced information technology and computer technology, to construct a unified user management, resource management and authority management to achieve the resource sharing and business collaboration. Department business support system, it comprises the educational administration, scientific research management, student work, employment guidance, digital leaving school, human resources, assets and equipment, file management, practical teaching, laboratory, network teaching, and the informatization of library management system and financial management system. Mobile campus, the mobile application system of the campus unified management platform can carry out the integration, excavation and reveal of all kinds of information resources and application services to provide convenient mobile information services for managers, 
faculty, parents and the public. Campus e-card system, it comprises library card, meal card, student card, work card, medical card, computer card, attendance card, entrance card, etc. Comprehensive security prevention system, it applies the monitoring equipment to carry on the all-directional, all-HD video three-dimensional management and monitor to the campus. Multimedia classroom, it can realize the terminal interactive teaching and mobile teaching under the cloud structure. Campus energy management system, it can carry out the power quality monitoring and management of power supply and distribution network. Campus geographic information system, it comprises 3D virtual campus subsystem, school administration facility management subsystem, campus comprehensive pipeline subsystem, campus real estate management subsystem, and background management subsystem. Educational resources, Online education platform, it is the online education and learning platform comprising the online teaching, online learning and management. Industry curriculum resource base, industry standard teaching resource base. Characteristic education resources management system, management system relating to the characteristic specialty education resources database[6].

\section{Characteristics and Objectives of Smart Education.}

Technical characteristics. Wireless campus environment with full coverage, Wireless network not only covers the traditional classroom and teaching environment, but also provides the outdoor wireless network system covering the whole campus, which can realize the support of the wireless campus network environment and provide the network foundation for many wireless applications. Cloud platform for core data center and backup data center, The cloud data center is constructed with uniform technical standard to ensure the maximum utilization of computing and storage resources. Therefore, the resources can be allocated in a unified way, and can be allocated independently by various business departments under different network conditions and application requirements. Shared data center based on big data technology, Shared data center can provide the data interface with uniform standard to manage and apply the data uniformly. With the support of big data technology, the data will be transferred to the top level application system more effectively and accurately, so as to realize more comprehensive, accurate, intelligent and perfect smart education application. Rich and comprehensive online educational resources, The online education platform can not only transfer the traditional teaching resources, but also establish the characteristic industry teaching resources base, which can realize the self-learning and enrichment in the teaching activities, and finally to form the unique teaching resources system of colleges and universities, moreover, it can provide the forward-looking knowledge accumulation for the characteristics of professional education[7].

Business characteristics. The linkage of all kinds of infrastructure and the information system can be realized through the vertical management line, horizontal cross-departmental cooperation line, and technical means to form the campus information environment with the extremely high synergetic ability and the regulation ability. Service-oriented, Taking "service-oriented" as the most basic construction principle, aiming at the four application systems of management, teaching, learning and life, the business management information platform with different types of users as the center has been established to break the traditional management thinking centered on the management department, so as to better service the teachers and students, and better support the management decisions. "People-oriented" business application system, The teaching application system has built the corresponding application modules based on the teacher-oriented and student-oriented, respectively. Moreover, the business application system for teachers and students will be connected organically to realize data sharing and organic integration of teachers and students' business systems, so as to create a convenient, fast and humanized campus life for teachers and students. Optimize management process and create integrated application, The scientific decision system is adopted to optimize the management process and create an integrated application based on the actual campus management application. Construction of intelligent decision analysis service application, The final 
goal of "deposit data" is applied to build a shared database to ensure the authority and consistency of the data used in each system. Standardized information standards can ensure the data consistency, integrity and accuracy of all business systems throughout the school, so that the availability, understandability, reliability and availability of the basic data are improved in terms of data quality.

\section{Three systems of smart education.}

Efficient campus management system. The real-time, efficient and unified management and control can be carried out to the campus basic services, security, administrative office, educational administration logistics, energy assets, space geography and other aspects through the campus application system construction of campus basic network, security prevention, daily office, information security, and energy asset management [8].

Intelligent teaching process system. From the two aspects of vocational training education and training education, the intelligent management and control of the main activities of the campus teaching process can be realized through the construction of the application systems, such as through smart classroom, distance education, virtual laboratory, electronic examination room, practical teaching, and vocational training certification [9].

Happy campus life system. the happiness index of the campus life of teachers and students can be improved from transportation, living, entertainment and other aspects in the daily life, through application system construction of campus e-card, digital library, campus television broadcast, campus information release, campus public application, campus medical, and campus environment monitoring[10].

\section{Conclusions}

The three application systems of smart education are not independent of each other, but intersects necessarily, which is one of the common characteristics of information system construction. Planning should be carried out in a comprehensive, multidimensional, phased and modular manner. Create a smart education unified management platform characterized in information collection, resource sharing, integrated application and integrated operation by taking the Internet of Things as the network foundation of information collection, circulation and exchange, and taking cloud computing and big data as the core technology of data storage, mining and analysis. The application system of smart education characterized in efficient, intelligent and happy can be established by modern high and new information technology, practical communication system, and innovative integration idea, so as to meet the growing demands of all levels of campus development. The happiness of campus life of teachers and students can be improved through the realization of high efficient campus management and the intelligentized teaching process on the platform of unified management of smart education.

\section{Acknowledgements}

First and foremost, I would like to thank my workmate Manling Cheng for his help in investigation and requirements analysis. Besides, the campus network in Wuhan Business University as an experimental base plays an important role in this research. Last but not least, the research is financially supported by the Special Project for Knowledge Innovation (Natural Science Foundation) of Hubei province (2018CFC901).

\section{References}

[1] Ping Zong, Hongbo Zhu, Gang Huang and Jianzhen Xu: submitted to Learned Journal of Nanjing University. Vol.30:4 (2010), p 15-19.

[2] Ronghuai Huang, Jinbao Zhang, Yongbin Hu and Junfeng Yang: submitted to Journal of open Education Research. Vol.18:4 (2012), p12-17. 
[3] Qian Lv: submitted to Journal of Computer Science. Vol.38:10A (2011), p18-21.

[4] Yuxing Huang, Qi Li: submitted to Journal of Southeast Academic. Vol.6 (2012), p309-316.

[5] Guanglin Lei, Jun Li: submitted to Journal of Logistics Technology. Vol.31:9 (2012), p414-416.

[6] Jinbao Zhang, Ronghuai Huang and Liangang Zhang: submitted to Journal of Open Education Research. Vol.18:3 (2012), p20-26.

[7] Dongxing Jiang.et al: submitted to Journal of East China Normal University. Vol.S1 (2015), p119-125.

[8] Junfeng Luo.et al: submitted to Journal of ICT in Education. Vol.3 (2014), p11-13.

[9] Jing-yan Zhao.et al: submitted to Journal of Information Science. Vol.34 (2016), p92-95.

[10] CHENG Xue-Qi.et al: submitted to Journal of Software. Vol.25 (2014), p1889-1908. 